\title{
SEVERE PERTUSSIS IN AN INFANT
}

\author{
Ekaterina Vlkova, Margarita Gospodinova \\ Department of Infectious diseases, Parasitology and Dermatology, Faculty of Medicine, \\ Medical University of Varna
}

\begin{abstract}
Despite high vaccine coverage, pertussis remains a global health concern. Recently, the incidence of infection has risen in Europe and other developed countries. Healthcare providers should be aware of the possibility of pertussis not only among unvaccinated infants but also among adolescents and adults, in whom pertussis often is misdiagnosed.
\end{abstract}

Keywords: pertussis, acellular pertussis vaccine, infant, cough

Pertussis is a highly contagious, vaccinepreventable illness caused by Bordetella pertussis (1). After a decline in the reported incidence of pertussis following the introduction of pertussis vaccines into national immunization programmes, reported pertussis incidence has increased in recent years in Europe (2). Possible reasons for the observed increase include changes in diagnostic testing, mismatch of vaccine antigens and circulating strains, and reduced duration of immunity from acellular pertussis (aP) vaccines (3). The most affected age group are infants under one year of age, who often show a severe clinical course of the disease (2).

A 3-month-old female infant with no past medical history was admitted to the Infectious Diseases Department of the St. Marina University Hospital, Varna with cough with 1-month duration, posttus-

Address for correspondence:

Ekaterina Vlkova

Faculty of Medicine

Medical University of Varna

55 Marin Drinov St

9002 Varna

e-mail:evalkova83@gmail.com

Received: April 22, 2019

Accepted: June 16, 2019 sive emesis and apnea. She was treated symptomatically in outpatient settings, without clinical improvement. The baby was born at term by Cesarean section with no remarkable neonatal events and weighed $3050 \mathrm{~g}$ at birth. She had no history of diphtheria-pertussis-tetanus (DPT) vaccination. Her mother had prolonged cough before the baby became ill.

On admission, she looked severely ill, with a poor mental response and normal body temperature. She had paroxysms of whooping cough with perioral cyanosis. Auscultation of the lungs revealed bilateral diffuse rales. Her respiratory rate was 47 and the pulse rate -130 . The remainder of her physical examination was normal. Laboratory tests showed leukocytosis with absolute lymphocytosis: hemoglobin $101 \mathrm{~g} / \mathrm{L}$, erythrocytes $3.65 \times 10^{12} / \mathrm{L}$, leukocytes $19.00 \times 10^{9} / \mathrm{L}$, neutrophils $8.50 \%$, basophils $0.10 \%$, monocytes $10.20 \%$, eosinophils $3.10 \%$, lymphocytes $78.10 \%$, platelets $362 \times 10^{12} / \mathrm{L}$. Compensated respiratory acidosis and hypoxemia were revealed: $\mathrm{pH}$ 7.392, pCO2 $6.01 \mathrm{kPa}$, pO2 $6.54 \mathrm{kPa}, \mathrm{HCO} 310.72 \mathrm{mmol} / \mathrm{L}$, $\mathrm{BE}-18.3 \mathrm{mmol} / \mathrm{L}$, O2SAT $85.2 \%$. C-reactive protein level and electrolytes were in normal range. We conducted a chest X-ray to detect lung abnormalities. It showed normal results.

We had the following reasons to doubt pertussis in this case: paroxysms of whooping cough with peri- 
oral cyanosis in an unvaccinated infant, who had been in contact with her mother who suffered a suspicious cough. Polymerase chain reaction (PCR) of theinfant's nasopharyngeal secretions was performed and showed a positive result for DNA of B. pertussis.

Our patient was treated with azithromycin, intravenous fluids, and oxygenation via a face mask. As a result of these measures, her clinical condition improved quickly, the paroxysms of whooping cough were stopped and she was eating the second day after admission. The infant was discharged in unremarkable condition without any neurologic complication 10 days after admission. The follow-up examinations showed no signs of abnormalities in her condition. We recommended to continue vaccinations as per schedule, but with the baby being given the DT vaccine instead of DPT for the remaining doses.

Since 2009, the herd immunity in Bulgaria has been supported by five-time shots of the aP vaccine (4). Bulgaria is an area with high vaccination coverage: $92.1 \%$ of the population is vaccinated with three doses of aP vaccine. Despite this fact, our country is experiencing significantly higher numbers of pertussis cases. In recent years, the epidemiology of pertussis has been changed: an increasing burden of disease among adolescents and adults has been observed in developed countries $(2,5,6)$. In attempt to protect infants, additional booster dose for adults and maternal immunization have been included in the routine immunization schedules in a number of European countries and the USA $(7,8,9)$. These measures show high effectiveness in the reduction of pertussis-related morbidity and mortality among infants (10).

In our case, we supposed household transmission of pertussis from the infant's mother, who suffered from a prolonged cough, to her daughter. Because the amount of bacterial DNA in the nasopharynx diminishes after the fourth week of cough (11) we did not test the baby's mother, who reported a cough onset 6 weeks prior with full recovery at the time of infant's admission. The clinical presentation of pertussis in infants is usually dramatic (9), as was observed in our patient: she was administered with compensated respiratory acidosis and hypoxemia. Early diagnosis and adequate therapeutic measures have led to an uncomplicated course of the disease in our patient. Our case shows that better control of the disease is needed. Surveillance of pertussis should be improved in order to assess the real epidemiological situation, especially among adolescents and adults as the source of infection for infants.

Since 2009 in Bulgaria whole-cell pertussis $(w \mathrm{P})$ vaccines have been replaced by aP vaccines because of safety concerns. But there are no current serosurveys, which assess the duration of immunity induced by $\mathrm{wP}$ and $\mathrm{aP}$ vaccines in different age groups. Consequently, a question remains open: does the vaccination strategy need to be revised and additional booster doses administered to adolescents, adults and pregnant women?

\section{Conflict of Interest Statement:}

The authors declare that there is no conflict of interest.

The authors received no specific funding for this work.

\section{REFERENCES}

1. Tian SF, Wang HM, Deng JK. Fatal malignant pertussis with hyperleukocytosis in a Chinese infant: A case report and literature review. Medicine (Baltimore). 2018;97(17):e0549. doi: 10.1097/MD.0000000000010549.

2. European Centre for Disease Prevention and Control. Pertussis. In: ECDC. Annual epidemiological report for 2015. Stockholm: ECDC; 2017. Available from: https://ecdc.europa.eu/sites/ portal/files/documents/AER_for_2015-pertussis. pdf

3. Skoff TH, Baumbach J, Cieslak PR. Tracking pertussis and evaluating control measures through Enhanced Pertussis Surveillance, emerging infections program, United States. Emerg Infect Dis. 2015;21(9):1568-73. doi: 10.3201/ eid2109.150023.

4. Kurchatova A, Vladimirova N, Minkova A. Analiz na izpalnenieto na dejnostite po imunoprofilaktikata v Balgariya prez 2016g. Nacionalen centar po zarazni i parazitni bolesti, otdel „Epidemiologiya i nadzor na zaraznite bolesti“ Available from: https:// www.ncipd.org/index.php?option $=\mathrm{com}_{-}$ docman\&view $=$ download\&alias $=122$-analysis immuno-activities\&category_slug=epidemiologiyai-nadzor\&Itemid=1127\&lang=bg\&lang=bg. (in Bulgarian). 
5. Kurchatova A, Vladimirova N, Minkova A, Kamenov G, Stoiczova S, Parmakova K. Ostri zarazni bolesti v Balgariya prez 2017g. (Osnovni epidemiologichni pokazateli) Available from: https://www.ncipd.org/index.php?option=com docman\&view=download\&alias $=128$ analysis-2017\&category_slug=analysis2017\&Itemid=1127\&lang=bg. (in Bulgarian).

6. Tiwari T, Murphy TV, Moran J, National Immunization Program, CDC. Recommended antimicrobial agents for the treatment and postexposure prophylaxis of pertussis: 2005 CDC Guidelines. MMWR Recomm Rep. 2005; 54(RR-14):1-16.

7. European Centre for Disease Prevention and Control. Vaccine schedule. [internet]. Stockholm: ECDC; 2017. Available from: http://vaccineschedule.ecdc.europa.eu/Pages/Scheduler.aspx.

8. Public Health England. Vaccination against pertussis (whooping cough) for pregnant women. [internet]. London: Public Health England; 2016. Available from: https://www.gov.uk/government/ publications/vaccinationagainst-pertussiswhooping-cough-for-pregnant-women.
9. Liang JL, Tiwari T, Moro P, Messonnier NE, Reingold A, Sawyer M, et al. Prevention of pertussis, tetanus, and diphtheria with vaccines in the United States: Recommendations of the advisory committee on immunization practices (ACIP). MMWR Recomm Rep. 2018;67(No. RR2):1-44. doi: 10.15585/mmwr.rr6702a1.

10. Amirthalingam G, Campbell H, Ribeiro S, Fry NK, Ramsay M, Miller E, et al. Sustained effectiveness of the maternal pertussis immunization program in England 3 years following introduction. Clin Infect Dis. 2016;63(suppl 4):S236-S43. doi: 10.1093/ cid/ciw559.

11. US Centers for Disease Control and Prevention (CDC). Pertussis. 21.11.2019. Available from: https://www.cdc.gov/pertussis/clinical/diagnostictesting/diagnosis-confirmation.html 